\title{
Logics of "Good teaching": Exploring Mathematics Education in Primary School in Sweden
}

\author{
By Kristina Holmberg* \\ Lisbeth Ranagården ${ }^{\dagger}$
}

The public and academic debate about mathematics education has been intensified during the last decade. In relation to this it is important to investigate what ideas concerning mathematics education that are expressed by teachers and students. The aim of this article is to study how teachers and students in primary school talk about the math book and to emphasize, discuss and problematize emerging discourses. The article is part of a larger project about mathematical education. Data consists of group conversations with 120 students and 8 teachers in two elementary schools in Sweden. The math project was supported by the National Agency for Education 2010-2012. All together 17 hours of video and audio documentation were produced. The theoretical framework is built on poststructuralist and social constructionist theory and two approaches to discourse analysis are applied; the micro oriented discursive psychology as formulated by Potter, and discourse theory as formulated by Laclau and Mouffe. Findings show three prominent discourses emerging from the empirical data: School mathematics, Balance and Mathematical ontology. Related to earlier research in mathematics education this article represent a shift of interpretation as it highlights how teachers and students themselves are talking about and describing what is desirable and not. The results are then discussed with respect to quality in mathematics education.

Keywords: discourse, ideological dilemma, mathematics, mathematics education

\section{Introduction}

During the last decade, mathematics education in Sweden has been subject to an intensive debate. All together, reports from PISA and TIMSS revealing deteriorating student results, rising status for school questions in political debates, and millions of Swedish crowns invested to improve results in mathematics, have transformed mathematics education into a central public issue. Also, the number of international scientific publications in mathematical education has tripled since year 2002 (Summon ${ }^{\mathrm{TM}}$ search, 2014), indicating a

${ }^{*}$ Lecturer, Halmstad University, Sweden.

${ }^{\dagger}$ Lecturer, Halmstad University, Sweden. 
growing international interest among researchers. In a survey, Pais and Valero (2012) point out that research objects to a large extent are focused on developing and optimizing learning in mathematics. Often the poor school results are used as an argument to legitimate the research object. Pais and Valero (2012) also emphasize that many studies have an ambition to manage what is usually called the social and political turn, but that these aspects often ends up as an isolated parallel to the main track of teaching and learning in mathematics. They identify three distinct areas:

1. Mathematics education research as learning and teaching mathematics in psychological and mathematical frames. Social, political and cultural factors are handled as if they were separated from the mathematical learning.

2. Mathematics education research is implemented to improve teaching and learning in mathematics. Frequent arguments are that good mathematics education creates a better society by developing "intelligence, spreading high morals, strengthening self-confidence and consolidating democracy" (p. 12).

3. Mathematics education is kept apart from other teaching subjects. It is learning in mathematics that is studied, which is not explored outside the realm of mathematics, for example, from a more general educational perspective.

To put mathematics at the centre of attention is desirable in many respects, but the isolation in relation to other school subjects and to society becomes problematic. It creates a field of research with its own self-defined problems, where those problems are claimed to be solved only within the field itself. Mathematics is also assigned to a prominent position in society, with a strong belief that mathematical knowledge, by itself, is good for both people and society. In accordance with Pais and Valero (2012), we are convinced that research in mathematics education can benefit from alternative viewpoints by challenging research perspectives to the three dominant approaches mentioned above. Therefore we have approached the research field in order to identify alternatives. We have no ambition to make a complete survey of the research. Instead our aim has been to display examples of a shift of focus.

Swanson and Williams (2014) are managing the relationship between abstract and concrete in mathematics education as they challenge the idea of a separation between cognition and activity. They advocate a neo-Vygotskian unified understanding and suggest ways to integrate thought and activity in teaching and learning. Theoretical mathematical concepts are made concrete in a meaningful practice. They argue that this is a way to avoid formal ritualised and fossilised settings. Lerman (2013) as well Pais and Valero (2012) problematizes that much research in mathematics education is about how teaching should be done, i.e. "good teaching" based on a normative research perspective. Instead, he suggests more studies to be directed towards what happens in practice. He asks for multiple stories about learning and teaching in 
mathematics. On this basis he sets out how the dissolution between theory and practice in relation to mathematics teaching and teacher training could be done. Masingila, Muthwii and Kimani (2011) emphasize the distinction between everyday mathematics and classroom mathematics. The study is based on the idea that students' power of mathematics increases if out-of-school situations are used at a larger extent. More specific, focus is on how students perceive that they use mathematics and science in out-of-school situations. With a framework of ethno sciences and ethno mathematics the researchers want to gain knowledge about students' use of mathematics and science in everyday activities. Although the results have a shaky reliability where quantification of the results overshadows the qualitative analysis, the article is an important contribution. The discussion points out the incorporation of students' ideas in education as prominent to create an inclusive education addressed to all children. We get a glimpse of an inductive ambition, but the results show a normative approach (Lerman, 2013) as "good teaching" becomes the incorporation of students' everyday mathematics in the classroom.

The above papers show tendencies for alternative directions in research carried out in mathematics education. This also implies a certain displacement from the three dominant areas identified as strong in mathematics education (Pais \& Valero, 2012). We, as well as others, are engaged in mathematics education to develop knowledge that can enhance quality. To do that, our framework in this article is a social constructionist perspective (Burr, 1995; Potter, 1996; Potter \& Wetherell, 1987) where the overall task is to highlight norms and values interwoven into practice. We are interested in discourses that create possibilities and constrains in mathematics teaching. By identifying discourses also cultural and social premises for practice are emerging, as they are an inseparable part of the discourses. In this perspective the researchers' task is to make visible and to problematize the ideas that characterize mathematics education. According to Ryve (2011), the number of articles studying discourses related to mathematical education has increased, and he points out the importance of conducting more studies using well-formulated theoretical perspectives. In line with this, our article is using a discourse analytical approach as described above to investigate the field of mathematics education.

With social constructionism as our theoretical framework, we intend to further explore the ideas of teachers and students regarding the math book. The reason is that we in a larger interview study of mathematics education in two Swedish primary schools (age 6-12) discovered that teachers and students talk a lot, and in many ways, about the math book, which aroused our interest to further investigate the rhetoric. With discourse analysis the interpretation preference moves away from the researcher and becomes closer to the practitioners in the field (Laclau \& Mouffe, 1985; Potter, 1996; Potter \& Wetherell, 1987). In line with Lerman (2013) our starting point will be the small stories. Hereby our study becomes one of many studies that produce knowledge about what is important for the actors in the field of mathematics 
education. Such an approach is a shift from how mathematics teaching "should" be to how it is "described" by people involved in the activities. Thus, we as researchers take a step aside in favour of the ideas emerging on the field. Our task will then be to make visible the rhetoric about the math book and to discuss and problematize those ideas. Based on what we have discussed above, the aim of this article is to study how teachers and students in primary school talk about the math book and to emphasize, discuss and problematize emerging discourses. Our research questions are: What rhetoric concerning the math book is emerging in the conversations? How is "good teaching" related to the math book articulated by the participants? What discourses are active in the constructions of the math book? Can any ideological dilemma be identified in the analytical results?

\section{Theory and Method}

Two approaches to discourse analysis are used, both founded in poststructuralist and social constructionist theory (Laclau \& Mouffe, 1985; Potter, 1996; Potter \& Wetherell, 1987). In discursive psychology, the sensitivity to various accounts of reality, and how knowledge is made persuasive is argued for (Potter, 1996; Potter \& Wetherell, 1987). The preference is that knowledge continuously is being constructed by actors in an ever on-going rhetoric battle. Discursive psychology emphasises the rhetoric and how different acts of speech can become convincing in the social arena. Another analytical aspect is the researchers creation of hypothesis related to possible consequences that different utterances in a conversation might have (Potter, 1996). By paying attention to this, the analysis can be further extended and the strategies that legitimize actions may become visible. This conversation analysis is a way to identify the rhetorical resources and the repertoires used in talk.

These repertoires are also important when discourses are the main interest, as they are in discourse theory formulated by Laclau and Mouffe (1985). Central in this theory is the logic of equivalence and difference applied to identify and demarcate discourses that are utilized in conversations. Discourse maps emerge and become visible to the researcher by building chains of equivalence. But discourse theory might as well be used complementary with discursive psychology (Ericsson, 2006; Holmberg, 2010). The discourse analytical posture is that everything always can be different, and that there always are alternative stories to tell (Burr, 1995).

This article is part of a larger project where elementary teachers' and students' discussions about mathematical education are investigated. Data consists of group conversations with 120 students and 8 teachers in two elementary schools in Sweden. The age range in elementary school is normally 6-12 years, but also recently immigrated students that were at the age of 13-14 years were part of the study. All participants were interviewed in smaller groups of 3-10 persons. In line with the discourse approach (Potter, 1996) our 
interest during those discussions concerning mathematics education were addressed to the participants' everyday talk and argument. Focus of the conversations was discussion themes where we as researchers wanted the participants to talk about: mathematics, mathematics education and school activities related to this. The participants were interviewed in groups in the beginning and in the end of a math project that was supported by the National Agency for Education 2010-2012. The schools were also selected to our study, as they were part of this national project. As there were no identified differences between the group interviews made in the beginning and in the end of the project, we decided to analyse all interviews as one unit. Although the empirical material was produced at two schools no such categorization were made in the implementation of the analyses. The reason is that research focus is on different ways to talk about mathematics education, so such distinction was not considered relevant. All together 17 hours of video and audio documented empirical material were produced.

Focus of analysis is excerpts emanating from group discussions with teachers and students. The quotations are chosen to represent different repertoires, which also helps to organize the results. In the empirical material, a large amount of utterances present similar examples as the chosen excerpts and repertoires. A reduction of the number of quotations has been made in accordance with the theoretical perspective (Potter, 1996). Therefore, all identified repertoires are represented by only one or two excerpts. Some of the quotes are also possible to conform in more than one repertoire, which is not considered as a problem in a discourse analytical approach.

In the results of this article the "good" mathematics education should be understood as a discursive construction. To clarify this, quotation marks are used consistently thoroughly when we want to point at a concept as a local and temporal articulation.

\section{The Math Book}

In the following, five repertoires that in varied ways highlight the math book related to mathematics education are presented.

\section{The Book as a Symbol for Security and Support}

\section{Teacher}

Doris: For me it would have been very difficult to put the math book aside... probably I would not trust myself... that I would bring everything in... then I would probably take a peak to see that I got all parts and stuff... and things.

This utterance is handling teachers' trust in their own skills and their confidence in the math book. According to this teacher, the math book is 
defining the content of the mathematics education. It becomes a checklist used to support the teacher who thereby can keep track of different mathematical topics. The large confidence in the math book enhances the authors' influence in mathematics teaching, where no considerations concerning the interests from the student group can be taken into account. In this perspective, the teachers' knowledge about mathematics and learning becomes marginalized. The teachers' task is merely to ensure that students do the tasks in the math book.

Thus, mathematics education is hegemonized by the math book, where the teacher becomes positioned as a communicator of a given content rather than as a responsible leader of different learning goals.

The "good" mathematics education is formulated as equal with the content of the math book.

\section{The Book Associated with Traditional and Abstract Mathematical Education}

\section{Teacher}

Margaret: I think that we have way too much written math... if we make it practical the kids can follow but when we come inside again and are working in the math books it is completely gone... I would like to work more with practical mathematics and diminish the abstract.

The problem raised by this teacher concerns the translation between practical and abstract mathematics. Learning is described as successful when it comes to practical mathematics, but the same content managed in a more abstract way, seems to imply difficulties for student learning.

The statement also reveals an ambition for change, where the teacher would like practical mathematics to claim more space in mathematics education. Also, this account says that mathematics education provided at the present time is more abstract. This rhetoric is based on the idea that teaching should focus on activities that are successful for student learning, an convincing argument. On the other hand, what is not working will not be problematized and in the next step developed. As a result, the transformation from concrete to abstract is not considered a knowledge that needs to be a part of teaching and student learning.

The math book is constructed as abstract and insufficient. The dominating way of teaching of mathematics emanates from the book. No desire to exclude the math book is expressed. Instead, the proposal is that the amount of teaching based on the book will decrease. The "good" mathematics education is constructed as a combination of a successful practical mathematics and a math book oriented problematic and abstract mathematics.

The issue is handling the difficulty of getting the abstract and practical mathematics intertwined. 


\section{The Book as the Home of Mathematics}

\section{Teachers}

Kate: [...] there are not so many kids who think math is something useful, it is for the school... it becomes so abstract and then it's another thing when you make it practical... .

Doris: Oh no, it's not math anymore... if one has not worked in the math book one has not worked with mathematics... .

According to this quote the students often construct mathematics as a school issue and not to everyday life or life outside school. Mathematics is tied to the math book while practical mathematics is not articulated as mathematics.

\section{Students 9-11 years old}

Shirley: what is mathematics... tell us some different things so we can understand what you mean. $(7 \mathrm{sec})$ thus... $(2 \mathrm{sec})$ I don't know really... .

Leo: no, me neither... .

Shirley: me neither... (laughs a little bit).

Hamish: (turns straight toward the camera and says very seriously an in a firm voice) no... mm... aha... plus, times... minus... (beats his hands together on the table in front of him and looks very proud).

Shirley: mm.. it's... (4 sec).

Hamish: I don't know... (mumbles something inaudible).

Shirley: thus, it is the things that are in the math book, type... .

Here, school mathematics is constructed as equated with the content offered by math books. Hypothetically, this is problematic because math skills are difficult to use in everyday life unless students can make connections to the world outside the math book. All pauses in the conversation also suggest that the question of what mathematics is, has urged the students to reflect. They have no quick answers, which may indicate that they have not discussed this earlier. As well, the question is not easy to answer. If teachers mostly use mathematical concepts when students are working with the math book, consequently math will be associated with the book. The teaching of mathematics that students in the conversation has been part of may be characterized as very practical mathematics, but if there is a lack of mathematical concepts in the discussion between teachers and students in these situations, the students can not be expected to make connections to mathematics.

In this perspective the math book becomes constructed as the creator of the boundaries of what mathematics can be. The mathematics is in math books, which in turn are in schools. Links to life outside school and to people's everyday lives are not made.

Mathematics education produced in the two excerpts above is based on the math book. No utterances can be tied to a rhetoric concerning the "good" 
mathematics education made by the teachers and students. Instead the quotes are interesting because they capture a repertoire that defines mathematics as the math book.

\section{The Book Decides Who is Smart and Who is Not}

\section{Teacher}

Alice: .... and then I relate this to the math book... is it because I should be on page 323 when the others are at $248 \ldots$ so, it's the book that is important or is it the fact that mathematics is a way of seeing reality and... I use the numbers to count... not as a way to see how far I've come in the math book.

This teacher is talking about mathematics teaching and the competition that the students often end up in, about who has advanced the furthest. In the quotation, the math book is created as a forum for the contest in which students with simple means can see how far they have come related to other students. Based on a rhetoric that revolves around the idea that those who find it easy with maths also are most advanced in math books, the book as a forum for contests becomes a way to measure how good you are. According to this, the teacher reflects on whether it is the math book or mathematics itself that is important.

The math book is constructed as limiting for the students learning in mathematics. The aspect that working in the math book easily goes to competitions is highlighted as problematic.

The "good" mathematics education is depicted as a teaching, which takes a broader look at mathematics than the math book can offer. Here a more philosophical approach is put forward that deals with mathematics as a perspective on reality.

\section{The Book Decides Who Needs Help and When to Wait for Help}

\section{Students 7-8 years old}

Manuel: sometimes it's a little... sometimes math is really hard... .

Kristina (researcher): and what is it that... .

Manuel: it's like when it's something we don't know, then I think it's hard, then you have to wait... well if you are really tired... .

Fred: then you have to wait and wait until your brain knows... .

Manuel: aah... (Sighs and lets his whole body collapse).

Kristina: okay, if I understand... if it is something that is awkward in the math book or when you're counting then you have to sit there and then you have to think about it yourself... .

Manuel: yes, but sometimes it is enough to raise your hand and the teacher will come... .

Kristina: yes.... 
This quote point out the individual work being done when the student sit alone and count in the math book. What seems to be frustrating for this student is that when he cannot solve a math task, he is supposed to wait. Either waiting means an individual effort where he himself should come up with a solution, or it means that he should raise his hand and wait for the teacher's assistance. Teaching in this conversation seems to be designed as individual work where students work on their own with their math books. This leads to a situation where the structure and progression of the book have a strong influence on whether a student needs help or not.

In the excerpt, waiting becomes a dominating part of what the students describes as problematic with mathematics education.

In the above conversation the math book is construed as a problem because it is used as a starting point for students' individual learning. If students have problems they should find out strategies on their own to solve the problems.

The quote above shows a construction of teaching that could be considered a contrast to "good" mathematics education. Waiting is described as a hassle and overall this indicates that the students would be happy to alter this practice. The "good" mathematics education could herby be described as an education where students do not have to wait and instead could be active and work with mathematics continuously.

\section{The Practical}

In the following, two repertoires that in varied ways highlight the practical mathematics in relation to mathematics education are presented.

\section{Practical Mathematics as Built on Students' Participation and Delight}

The students have just described a math game they usually do. It's a game that trains mental arithmetic and it's about succeeding with as many of the linked assignments as possible. When the students fail, which means that she no longer knows which number is the answer, she should sit down. At the end there is only one winning student left. After the description of the game the following conversation takes place:

\section{Students 12-14 years old}

Kristina (researcher): But what do you think of the game then... .

Mary, Amy and Felice: It's fun... .

Kristina: it's fun, but it's not difficult then... .

Felice: yes it is... .

Amy: or it's much more fun to do math then... .

Ethel: because you get more, thus you take in more... .

Amy: you do not learn as much if you just sit and work in a book... and only do the instructions... .

Ethel: no, then there will be no fun... . 
Amy: just sitting and becoming completely brainwashed... .

Kristina: but what's the funny part... it sounds... I think it sounds really hard... what's the fun... .

Marion: you have to think very much... .

Amy: it's a challenge... .

Marion: aah....

Kristina: okey... .

Marion: you have to keep track of it all the time, it's challenging that it's more difficult... it's no fun if it's too easy... if it's a bit difficult then it's fun....

Kristina: but it's not embarrassing when one can't... .

Amy: noo... .

Mary and Marion: noo... .

Amy: noo, there are not many that can do it... .

Mary: you've got to stand up for what you are... .

Marion: it's a pretty high level anyway; she says it very quickly so it's no wonder if you're out for the difficulty... .

Mary: yes it's difficult and it can be a little stressful, one can say... .

Ethel: they say high numbers... .

Kristina: yes that's right, it goes pretty fast... .

Mary: and high numbers... .

Amy: they say (talking fast) two times three divided by four, plus five, divided by three, very quickly and you just ba... ugh... de-de-de-de (wiggling her head sounding like a machine).

Marion: and she did't cope... it's very... you have to think... then you train a lot of math... .

According to this conversation the game is challenging, making the students think intensely. This teaching exercises the students' ability to keep multiple devices at mind, to remember and to do mathematical calculations. They believe it is difficult and that few succeed, but nevertheless the game is experienced as enjoyable and fun. Here, thinking is tied to mathematics and it seems that it creates meaningfulness to the students. They make clear that they exercise very much mathematics in this form of teaching.

Learning in mathematics is also discussed in a comparison between the math game and the math book. According to the students the math book is about instructions that do not support learning the way the game does. It seems like the desirable in a demanding game also promotes learning at a larger extent.

The math book is construed as limiting related to what a math game can offer. Working in the book just involves following instructions, which are not perceived as pleasurable.

The "good" mathematics education is produced as a practical mathematics that also focuses on developing student mathematical abilities, such as students' mathematical thinking. This teaching is also fun and challenging for students. 
For a while the teachers have been talking about practical mathematics where the students pretend to shop at Ullared [a very famous Swedish shopping centre with low prices] and working with the Idefix-house [a mini-house used for math tasks]

\section{Teacher}

Kristina (researcher): One last question... do you know that it's good to work like this... .

Amanda: What you can see is the joy.... the children are on pretty quick with ideas and then the imagination starts... we can se that they feel good when they're so so involved... and somewhere along the way they lose the joy of math but here it seems as also the slightly older kids like this and are engaged... .

According to this teacher, working with practical examples in mathematics education provides motivation and joy for the students. By involving the students and allowing them to create their own math tasks, they can use their imagination, which seems to contribute to motivation. This type of mathematics teaching also has a therapeutic function in the sense that the students get to feel good.

In the quotation, a parallel is drawn to a kind of normality where pupils through their education lose the joy of facing mathematics. Though the statement a line is drawn between the joy-killing education and their own joyful education. The specific mathematics advocated by the teacher, offers an education in which students, even though they get older, can continue to have involvement with mathematics.

Hypothetically, on the one hand, it is possible to provide the "normal education" with content, based on how the teacher describes the opposite, "the practical teaching". Practical mathematics teaching is articulated as something that creates the following chain of equivalence: Joy - Interest - Motivation Students can use their imagination - Students feel good - Participation Involvement. On the other hand, based on the logic of difference, the following chain of equivalence can be created to describe the "normal mathematics education": Not joy - Disinterest - Not motivation - nonparticipation. The normal education of mathematics is also articulated by being a contrast to the practical mathematics and can thus be constructed as abstract mathematics and the math book mathematics.

Based on the analysis made above, the math book is construed as a contrast to the mathematics teaching advocated by the teachers in the conversation, and the math book becomes completely excluded from a concrete everyday mathematics.

The "good" mathematics education is portrayed as a practical activity where students, starting from themselves and their interests, may shape the tasks that they should work with. This teaching becomes democratic by student influences, and this teaching creates delight and joy for the students. Finally, 
this teaching has a therapeutic dimension as it makes the students to feel good. The effects of such an education seems to create motivation among both younger and older students, something that the normal mathematics education fall down on, according to the analysis.

\section{Practical Mathematics as also Constructed around the Norms of the Book}

This example is really about mathematics content in a book in civics. The argument about how numbers and dimensions of the books should be handled in the teaching is the same as in mathematics teaching. It's also what the conversation revolves around when one of the teachers starts to talk about a math example in the book:

\section{Teacher}

Alice: Yes I'm a teacher in civics and we've talked about the Viking Age and been out on the scoolyard and measured how large Viking ships were... it was a totally different experience than just seeing a number in a book... one want to experience that, what one has learned is useful to know... also that the knowledge they have learned can be useful in another context... .

According to this teacher, working practically with mathematics gives other experiences than the abstractions found in the book. Usability aspects are also important. Students want to be ware of the practical utility of mathematics, and that lesson stuff also can be used in other contexts such as in the schoolyard. The mathematics in the example is about concrete dimensions of ships, as part of the teaching in Civics. According to the teacher it is the students' perception of size that is important.

Such reasoning has implications for the usefulness of the book as it in itself fails to provide students with experiences that they can achieve by translating mathematical abstractions into something concrete in reality. Also, by concretize through practical examples mathematical utility and usability becomes clear to students, which creates motivation.

The (math) book is construed as inadequate for student learning because it has a too abstract content. Knowledge is in the math book, but this is not sufficient for student learning. Also, to get the experience, benefits and relevance related to mathematics need a concrete and practical mathematics.

In this example, "good" mathematics education is articulated as a combination of books and practical exercises. The book defines the mathematic content, but for learning to take place, teachers need to turn knowledge into something concrete.

\section{Discussion}

In the first part the repertoires are discussed and structured around three discourses. In the second part the ideological dilemma is discussed. 


\section{The Math Book and the "Good" Mathematics Education}

The results show three discourses emerging from the empirical data: School mathematics, Balance and Mathematical ontology. They are all presented in detail below.

School mathematics. In The book as a symbol for security and support and in The book as the home of mathematics a strong link between math book and math teaching occur. Here, school mathematics is created which reveals difficulties to step outside school to relate to students everyday life. Also, when the definition of mathematics is limited to the math book the authors become a key player in education. The teachers' position is marginalized and the main task is to communicate a mathematical content that external actors decide.

Quality in this teaching is strongly linked to the math book and that all children should do the same things in the same order. It also embraces the idea that knowledge and exercises available in the math book are correct, so it can be used as a template for the optimized math content. The problem that emerges on the basis of such reasoning is the lack of considering students' influence. If the quality of this education should be developed it would primarily be directed to an improvement of the structure and format of the math book. This discourse provides a logic that keeps mathematics apart from other subjects (Pais \& Valero, 2012), confirming that this teaching may have difficulties with topic integrated learning designs. Hereby it will also be problematic to insert the mathematical content in other contexts than offered by the math book. Bridging the dichotomy between abstract and concrete will depend on the arrangements expressed in the math book (Swanson \& Williams, 2014). Although the link between school and everyday mathematics becomes complicated when the math book has such a prominent position. Pupils' influence must then stand back in favour of predestined subject content made by the math book, an aspect also problematized in previous research (Masingila, Muthwii, \& Kimani, 2011).

Balance. In the excerpts called: The book associated with traditional and abstract mathematical education, the book decides who needs help and when to wait for help and Practical mathematics as also structured around the norms of the book combinations of activities including both the math book and practical exercises are produced. The content of the math book is articulated as something abstract and insufficient to help the teaching achieve good quality. Rather the activities with the math book need to be complemented by practical and concrete teaching. Such teaching is successful because it manages to give students experiences of mathematics, the students will discover how abstract mathematics can be used in reality. The teacher occupies a strong position as the responsibility to balance the content largely rests on the teacher. This education also requires a teacher that is updated with students' level of skills so that the content can be customized.

Quality in this teaching is strongly linked to the integration between the abstract and the concrete. It is about creating balance and not to do too much of 
one or the other. In line with this reasoning, quality is improved through intensified integration where it becomes even clearer that the abstract and concrete presuppose each other. This discourse provides a logic that opens up for both integration with other substances (Pais \& Valero, 2012) and for integration between abstract and concrete mathematics (Swanson \& Williams, 2014). The proximity to students' everyday mathematics seems obvious which could also be a contribution to the strengthening of students' confidence in themselves in relation to mathematics. This is likewise an aspect in line with what Masingila, Muthwii and Kimani (2011) are asking for.

Mathematical ontology. In The book decides who is smart and who is not and Practical mathematics as built on students' participation and delight a mathematics education emerges that freed itself from the power of the math book when creating teaching content. Here, the reasoning is about mathematical skills, mathematical thinking and mathematical perspectives on reality. A mathematical ontology appears as a basis for teaching where students will discover the mathematical and practice on how to think mathematically. It is also interesting that challenging mathematics is portrayed as something positive and fun. This education also includes democratic aspects when students are given influence concerning the tasks. Perhaps the most surprising articulation is about the therapeutic dimension of this teaching, as the students are regarded as feeling good by doing mathematics this way. This teaching requires flexibility and creativity among both teachers and students.

Quality in this teaching stands out as a joint project for teachers and students. With the mathematical ontology as a starting point, greater creativity and more ideas can improve the quality. This discourse provides a logic that entirely revolves around a mathematical content. Pais and Valero (2012) criticize research with such a focus. In contrast, we show at an empirical level, that focusing on mathematics can have several advantages for teaching and learning. When mathematics is the object also the split between abstract and concrete mathematics, which is problematized by Swanson and Williams (2014), becomes unimportant. In other words, this shows that teaching revolved around abstract thought can be as valuable as a teaching revolved around concrete mathematics. For the same reason, the division between school and everyday mathematics put forward by Masingila, Muthwii and Kimani (2011), becomes insignificant.

\section{The Ideological Dilemma}

In several quotes the math book is described as somewhat problematic for the participants because of its power in teaching. The math book creates an educational content and forms a template where teachers can check the teaching content. At the same time a desire to work in a more concrete and practical way is expressed. Although the rhetoric revolves around the concrete and practical mathematics, the math book is there as the basis for the mathematical content, resulting in a dilemma for the teachers who can not fully work as they wish. The clearest example from the excerpts presented here is 
The book as a symbol for security and support. The dilemma appears to the teachers, as an uncertainty about their own math skills and therefore, the book has to be used as a support, even if the teachers might prefer to free themselves. If on the one hand, teachers completely rely their work on the math book, their own conviction that practical mathematics is preferable disappears. If on the other hand, the teacher only works with practical mathematics, the mathematical content would be lost as the teachers have no trust in their own math skills and therefore need the math book.

\section{Conclusions}

The results of this article emphasize three prominent discourses: School mathematics, Balance and Mathematical ontology, as well as an ideological dilemma. We are convinced that the results could be useful to teachers and researchers in the on-going development of the field of teaching, learning, and research in mathematics education. As other studies (Lerman, 2013; Pais and Valero, 2012), this article handles the "good" mathematics education, but from an alternative perspective. Our aim has not been to describe what is good mathematics teaching, but rather to highlight and discuss how teachers and students reason about mathematics teaching and thus on an analytical level to define what good mathematics teaching can be to actors in the field. This difference can be described as a shift of interpretation. What we do in this article is to highlight how the field itself is talking about and describing what is desirable and not in mathematics education. Such framework is demanded by Pais and Valero (2012) and Lerman (2013), while Masingila, Muthwii and Kimani (2011) has this frame as a starting point of their investigation. Based on this, our study seems to be both requisite and important to the teaching of mathematics. Our belief is that if mathematics knowledge and teaching of mathematics should be developed, teachers' and students' ideas need to be taken seriously. Otherwise there is an impending risk that researchers will construct a chimera that has weak connections to the problems identified by the actors in the educational field.

\section{Acknowledgments}

We want to thank the FULL research team at Halmstad University for valuable contributions in the project and specially Marie-Helene Zimmerman Nilsson for important comments on the manuscript.

\section{References}

Burr, V. (1995). An Introduction to Social Constructionism. London: Sage.

Ericsson, C. (2006). Terapi, Upplysning, Kamp och Likhet Till Varje Pris. Undervisningsideologier och Diskurser hos Lärare och Lärarstudenter i Musik. 
[Therapy, Enlightenment, Struggle and Equality at Any Cost. Educational Ideologies and Discourses among Teachers and Student Teachers of Music]. Malmö: Malmö Academy of Music.

Holmberg, K. (2010). Musik- och Kulturskolan i Senmoderniteten: Reservat eller Marknad [The Community School of Music And Art in Late Modernity: Reservation or Market?]. PhD Thesis. Malmö Academy of Music. Lund: Lunds Universitet.

Laclau, E., \& Mouffe, C. (1985). Hegemony and Socialist Strategy. Towards a Radical Democratic Politics. London: Verso.

Lerman, S. (2013). Theories in Practice: mathematics teaching and mathematics teacher education. ZDM. The International Journal of Mathematics Education, 45(4), 623-631.

Masingila, J. O., Muthwii, A. M., \& Kimani, P. M. (2011). Understanding students' out-of-school mathematics and science practice. International Journal of Science and Mathematics Education, 9(1), 89-108.

Pais, A., \& Valero, P. (2012). Researching research: mathematics education in the Political. Educational Studies in Mathematics, 80(1-2), 9-24.

Potter, J. (1996). Representing Reality. Discourse, Rhetoric and Social Construction. London: Sage.

Potter, J., \& Wetherell, M. (1987). Discourse and Social Psychology. London: Sage.

Ryve, A. (2011). Discourse Research in Mathematics Education: A critical evaluation of 108 journal articles. Journal for Research in Mathematics Education, 42(2), $167-198$.

Summon ${ }^{\mathrm{TM}}$ search (2014). Search words: "mathematics education". Retrieved from http://bit.ly/1Rw4DsZ.

Swanson, D., \& Williams, J. (2014). Making abstract mathematics concrete in and out of school. Educational Studies in Mathematics, 86(2), 193-209. 